\title{
Reinforced dental plaster with low setting expansion and enhanced microhardness
}

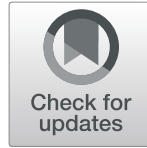

\author{
Tamer M. Hamdy ${ }^{1 *}\left(\mathbb{D}\right.$, Ali Abdelnabi ${ }^{1}$ (D) and Rasha M. Abdelraouf ${ }^{2}$ (D)
}

\begin{abstract}
Background: Three types of gypsum products were commonly used in dentistry to fabricate dental casts and dies which includes dental plaster, dental stone, and improved stone. Improved stone could be used as final casts and dies for building of final indirect dental restorations. Even though the cost of dental plaster is very low, their inherent lowest surface microhardness, compressive strength, and dimensional stability values confined their utilization as preliminary cast and die materials. This in vitro study was evaluated the effect of incorporation of 10 weight \% (wt.\%) aluminum oxide nanoparticle fillers on surface microhardness, compressive strength, and setting expansion of the dental plaster compared with the gold standard improved stone.

Methods: The control group was prepared by mixing dental plaster with water. The innovative reinforced dental plaster group was prepared by incorporation of $10 \mathrm{wt} . \%$ aluminum oxide nanoparticle fillers to the conventional one prior to water mixing. The improved stone group was prepared by mixing the improved stone with water. Chemical composition of the three group powders was determined using $x$-ray florescence spectrometer (XRF). The surface microhardness, compressive strength, and setting expansion were measured.

Results: The results revealed that innovative dental plaster reinforced by $10 \mathrm{wt} . \%$ aluminum oxide nanoparticle fillers was shown higher mean surface microhardness than that of conventional dental plaster, while higher mean compressive strength values than that of improved stones and conventional dental plaster. Moreover, reinforced dental plaster was shown lower mean setting expansion values compared with conventional dental plaster and improved stones ( $P$ value $\leq 0.05)$.
\end{abstract}

Conclusion: Within limitation of this study, the results are indicating the opportunity of the innovative reinforced dental plaster to be used alternatively to improved stone (type IV) for fabrication of final dental casts and dies.

Keywords: Dental plaster, Gypsum products, Aluminum oxide, Nanoparticles, Compressive strength, Microhardness, Setting expansion, Casts, Dies

\section{Background}

Gypsum products are one of the most broadly utilized dental materials for fabrication of dental casts and dies which are used as for further construction of indirect dental restorations. Gypsum products are obtained from natural gypsum minerals. The American Dental Association (ADA) classify gypsum products into five different types according to their properties and uses which are

\footnotetext{
*Correspondence: dr_tamer_hamdy@yahoo.com

${ }^{1}$ Restorative and Dental Materials Department, National Research Centre (NRC), El Bohouth St., Dokki, Giza 12622, Egypt

Full list of author information is available at the end of the article
}

impression plaster (type I), dental plaster (type II), dental stone (type III), improved stone (type IV), and high expansion improved stone (type V) (ADA 1985). All these gypsum products are chemically have the same composition which is calcium sulfate hemihydrate $\left(\mathrm{CaSo}_{4} \cdot 2 \mathrm{H}_{2} \mathrm{O}\right)$; they only differed in particle size and shape according to the manufacturing technique. Thus, each type have different mechanical properties (2012; Darvell 2018; Products 2018).

Dental cast is the positive replica of the prepared teeth and other structure of the dental arch. Dental die refers to the positive reproduction of the single prepared tooth. 
Dental plaster manufacturing process depends on rapid and direct heating of the calcium sulfate dihydrate in open air; thus, the resultant powder is weak, irregular porous particles. Improved stone undergo calcination in a calcium chloride solution to obtain more regular, denser, smaller, and strong particle (Razak et al. 2017).

Dental plaster is the least strength, stability, and cost than other gypsum products types. Therefore, dental plaster is used to fabricate preliminary dental cast (study cast) for a diagnostic purpose and to design the treatment plan. In order to construct indirect restorations outside the mouth such as inlays, onlays, dental crowns, and bridges, a final dental cast or die must first be fabricated. The final dental casts should be fabricated from a substance of a high surface microhardness, strength, and dimensional stability (Manappallil and Manappallil 2016).

Selection of which type of gypsum products to be used is influenced by their properties and application (Abdelaziz et al. 2002).The ideal requirement of gypsum products to be used as final cast materials comprises high surface microhardness to withstand scratching upon dental restoration preparation, a high compressive strength to resist manipulation force during laboratory steps. Moreover, minimum setting expansion (maximum dimensional stability) to possess accurate fitting of the final dental restoration (Kenyon et al. 2005).

Improved stone (type IV) is usually used to fabricate the final dental casts, owing to their premium mechanical properties such as great resistance to abrasion and high compressive strength, in addition to high accuracy due to little setting expansion when compared with other gypsum product types (Akkus et al. 2018). Despite of the advantages of dental plaster such as simple manipulation and their low cost, they suffer from low surface microhardness, low compressive strength, and high setting expansion (Subhan et al., 2016). The addition of fillers to gypsum products could be greatly modifies their properties and uses (De Cesero et al. 2017; Razak et al. 2017).

Some attempts have been conducted to enhance the compressive strength of gypsum products by incorporation of different inorganic additives fillers (Razak et al. 2017). Our previous study was established to highlight the possibility of using the aluminum oxide (15 wt.\%) in the conventional microsize particles as inorganic fillers to conventional dental plaster to enhance their mechanical properties and setting expansion to fit the minimal requirement to be used as type IV gypsum product (Hamdy, 2019). No previous studies compared the added element to dental plaster with the improved stone.

Implication of nanotechnology into composite materials could be greatly enhanced their properties (AlKahtani 2018). The nanoparticle fillers are estimated to incorporate more homogeneously than large microsized particle fillers inside the host (Safi 2014). Metal oxide nanoparticles have a great attention because of their stable structural behavior. Aluminum oxide nanostructured is considered as one of the most essential metal oxide material which is efficiently used in industrial applications (Ismail et al. 2017).

The current study was conducted to get the benefit of nanotechnology to incorporate aluminum oxide in nanoparticles in small amount of $10 \mathrm{wt} . \%$ in an attempt to improve the mechanical properties (surface microhardenss and compressive strength) of the conventional dental plaster and decrease their setting expansion, comparing the results with those of the gold standard improved stone (positive control) and conventional dental plaster (negative control) as a trial to get an alternative to the improved stone (type IV) with enhanced properties.

\section{Materials and methods}

Ninety specimens were prepared, which were divided into three groups $(n=10)$ in this in vitro study. The conventional dental plaster groups (control) were prepared by mixing dental plaster (Dental Plaster Type II, Garreco, USA) with water. The reinforced dental plaster groups were prepared by manually incorporation of 10 wt.\% aluminum oxide nanoparticle fillers $(99.9 \%,<50$ $\mathrm{nm}$ particle size) purchased from (Sigma-Aldrich, St. Louis, MO, USA) to the conventional dental plaster powder before water mixing. The improved stone groups were prepared by mixing improved stone powder (Royal Rock Type IV, Garreco, USA) to water. Water-topowder ratio was adjusted according to the manufacturer's instructions between all groups. The mixing of all types of gypsum products with water was done under vibrator (Plaster vibrator, Technoflux, USA) to get a uniform, homogeneous, smoothed mix, without air bubbles. The mix was poured into the prepared molds designed for each test. Chemical composition of the three group powders was determined using $\mathrm{x}$-ray florescence spectrometer (XRF) (Axios, Panalytical, Netherland).

Surface microhardness was evaluated according to ADA specification No. 25. Metallic mold $(40 \mathrm{~mm}$ in diameter and $10 \mathrm{~mm}$ in height) was constructed and filled with freshly mixed gypsum products, and specimens were removed after $1 \mathrm{~h}$. After $24 \mathrm{~h}$, specimens were tested for surface microhardness using Vickers hardness number (VHN) test ( 30-gram load for 30 s) (Fig. 1) (ADA 1985).

Compressive strength was measured according to ANSI/ADA No. 25. A metallic mold $(20 \mathrm{~mm}$ diameter and $40 \mathrm{~mm}$ height) was constructed and filled with freshly mixed gypsum products, and specimens were removed after $1 \mathrm{~h}$. After $24 \mathrm{~h}$, specimens were tested for compressive strength using Universal Testing Machine (Shimadzu Autograph AG-X plus, Kyoto, Japan) at crosshead speed of $1 \mathrm{~mm} / \mathrm{min}$ with load cell $5 \mathrm{KN}$ (Fig. 2) (ADA 1985). 


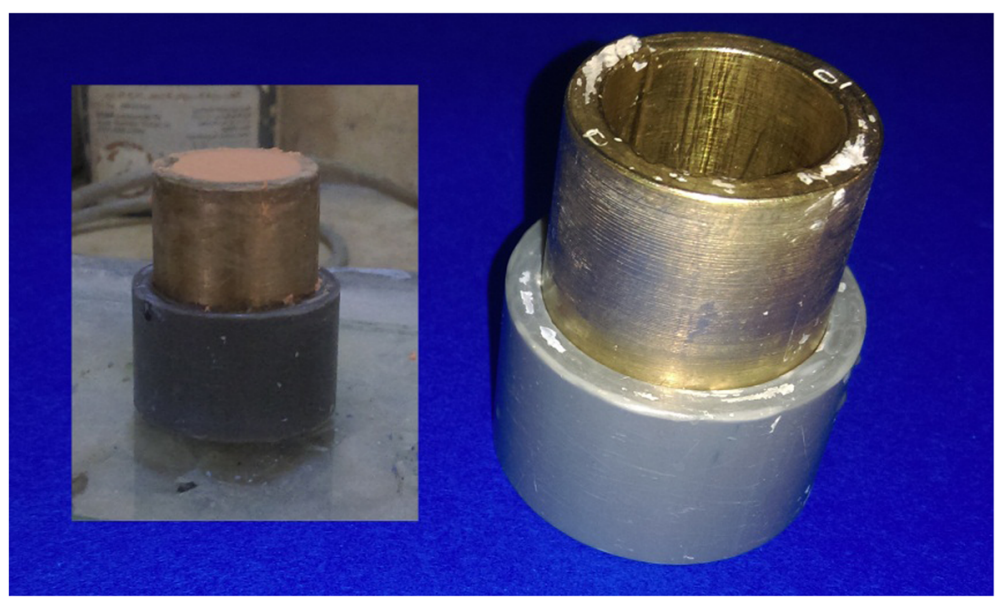

Fig. 1 Surface microhardness test mold

The setting expansion (dimensional change) was measured using extensometer (expansion) device with micrometric clock (Novanna, UK) (Fig. 3). The change in the volume of the gypsum during setting was recorded at $2 \mathrm{~h}$ after gypsum mixing by the micrometric clock in millimeter $(\mathrm{mm})$. The setting expansion was expressed as a percentage (dos Santos et al., 2015).

Statistical analysis was achieved by $\mathrm{IBM}^{\circ} \mathrm{SPSS}^{\circ}$ Statistics Version 20 for Windows (SPSS Inc., IBM Corporation; USA) using one-way analysis of Variance (ANOVA) and Tukey's honestly significant difference (HSD) test to compare the mean values of surface microhardness, compressive strength, and dimensional changes of the three groups. The significance level was set to $5 \%(P<0.05)$.

\section{Results}

The XRF analysis results of the three groups were expressed in Table 1. The results revealed the contained common various elements for each group. The reinforced dental plaster group shows aluminum oxide element nearly around $10 \mathrm{wt} . \%$ which confirms homogenous blending of the nano fillers to form the desired novel composite group.

Mean and standard deviations of surface microhardness, compressive strength, and dimensional changes (setting expansion) for groups were given in Table 2.

The conventional dental plaster showed the significant surface microhardness values, compared to the reinforced dental plaster and improved stone $(p<0.05)$, while no significant difference was detected between the surface microhardness of the reinforced dental plaster and that of improved stone $(p=0.83)$ as demonstrated in Fig. 4.

There was a significant difference between the compressive strength of the three groups $(p<0.05)$; the conventional dental plaster showed the least compressive strength, whereas the reinforced dental plaster showed the highest values as illustrated in Fig. 5.

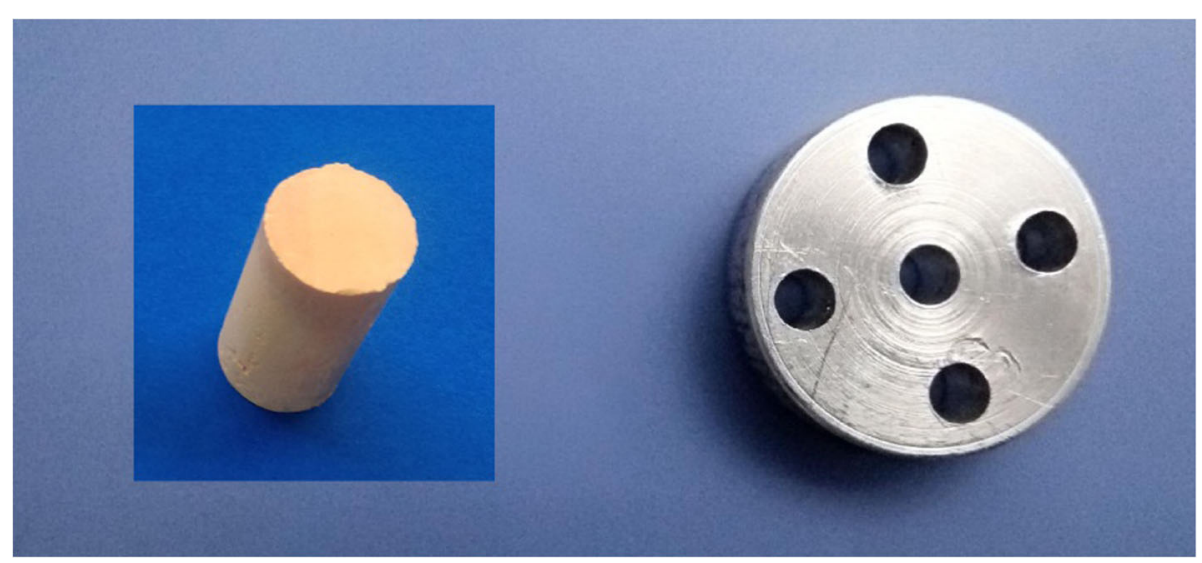

Fig. 2 Compressive strength test mold 


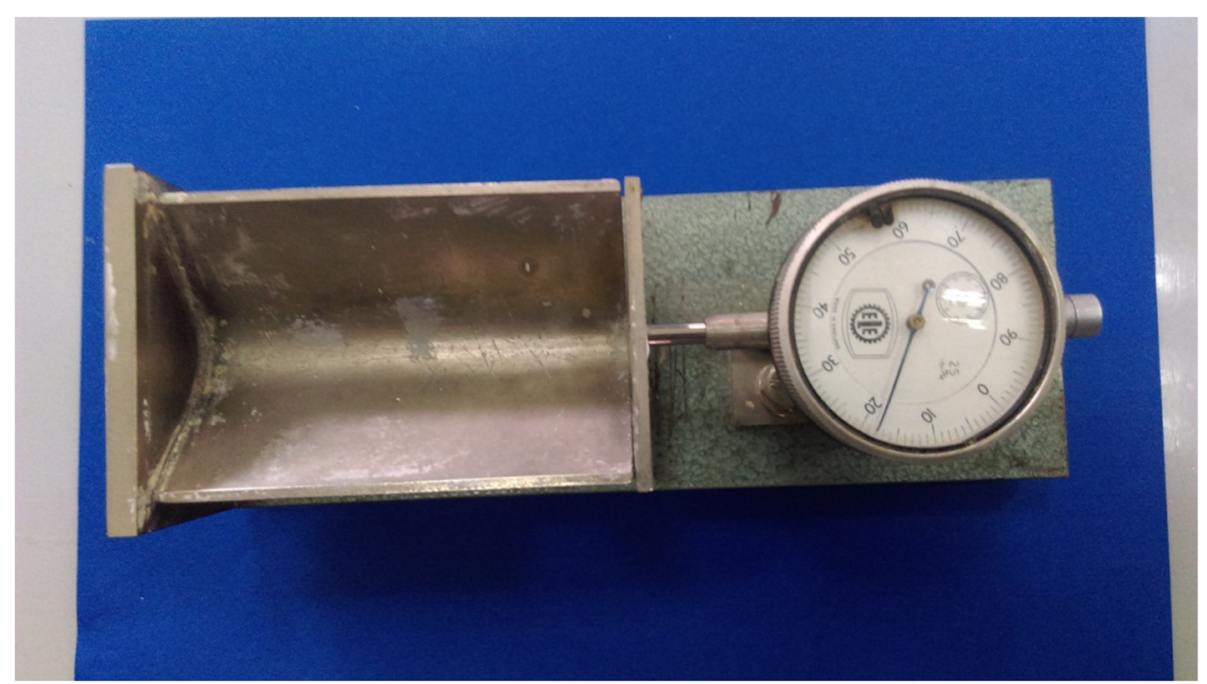

Fig. 3 Extensometer device with micrometric clock

The reinforced dental plaster showed the least significant dimensional changes (setting expansion), followed by the improved stone, while the maximum dimensional changes were found in the conventional dental plaster, with significant difference between the three groups $(p<$ 0.05) (Fig. 6).

\section{Discussion}

Surface microhardness and compressive strength are crucial parameters in fabrication of dental cast and dies to resist laboratory manipulative forces during indirect dental restoration construction. Moreover, the setting expansion (dimensional changes during setting) is a critical factor for the successful fabrication of accurate sized wax pattern and consequently dental restoration (Abdelaziz et al. 2002).

Several attempts have been performed to enhance the mechanical properties of dental plaster that include incorporation of various additives such as Arabic gum, silicone oxide, glass fibers, and calcium oxide (Razak et al. 2017; Akkus et al. 2018). In the current study, aluminum oxide nanoparticles have been used as fillers to reinforce the conventional dental plaster. The conventional dental plaster was used as negative control, while the improved stone was served as a positive control.

The set gypsum material final surface microhardness strength and setting expansion are prominently controlled by the crystal particle number and entanglement,

Table 1 The XRF element values (oxides wt.\%) of the powders of all groups

\begin{tabular}{lllllll}
\hline Oxides wt.\% & $\mathrm{SO}_{3}$ & $\mathrm{CaO}$ & $\mathrm{SiO}_{2}$ & $\mathrm{MgO}$ & $\mathrm{Al}_{2} \mathrm{O}_{3}$ & $\mathrm{Fe}_{2} \mathrm{O}_{3}$ \\
\hline Conventional dental plaster & 49.94 & 43.31 & 2.88 & 2.65 & 0.85 & 0.36 \\
Reinforced dental plaster & 46.00 & 38.02 & 2.36 & 2.45 & 10.9 & 0.26 \\
Improved stone & 47.49 & 42.1 & 3.95 & 4.81 & 1.10 & 0.53 \\
\hline
\end{tabular}

and any substance that inhibits the crystal growth or decrease their number will affect their strength and abrasion resistance (Jayaprakash et al. 2014).

The gypsum product materials utilized for construction of final casts or dies should express a high resistance to scratching and sufficient strength that withstand the manipulated force during laboratory manipulation and wax pattern construction, which in turn changed to final indirect dental restorations.

After calcium sulfate hemihydrate (gypsum products) mixing with water, they began to set and undergo dimensional changes. This expansion mostly is due to growth in both number and size of the growing calcium sulfate dihydrate crystals. Entanglements of the growing crystals push against each other lead to a phenomena called "crystal outward thrusting action." Expansion will occur as a result of occupying the crystals a larger space volume. Additionally, internal porosity in the set mass will be created due to the outward thrust action (Michalakis et al. 2012).

Minimization of the setting expansion of the gypsum products upon transformation of calcium sulfate hemihydrate to dihydrate to very little values is mandatory to get a proper fitting of the indirect dental restoration to tooth surface (Razak et al. 2017). Aluminum oxide nanoparticles are considered as a chemically inert ceramic, non-toxic, and white in color. It could serve as promising fillers into advanced dental materials. They have a great capability to produce act as reinforcing agent to increase surface microhardness and enhance the mechanical properties (Alhareb et al. 2017).

The null hypothesis was that there has no significant difference between the surface microhardness, compressive strength, and setting expansion between conventional and reinforced dental plaster with $10 \mathrm{wt} . \%$ aluminum oxide nanoparticles fillers. 
Table 2 The mean, standard deviation values and results of one-way ANOVA and Tukey's HSD test for comparison between surface microhardness, compressive strength, and dimensional changes of the groups

\begin{tabular}{|c|c|c|c|c|}
\hline Groups & & & & \\
\hline Mean & Conventional dental plaster & Reinforced dental plaster & Improved stone & $\boldsymbol{P}$ value \\
\hline Surface microhardness (VHN) & $64.4 \pm 3.8^{\mathrm{a}}$ & $124.3 \pm 4.9^{b}$ & $123.1 \pm 4.4^{b}$ & $\leq 0.001^{*}$ \\
\hline Compressive strength ( $\mathrm{MPa})$ & $7.8 \pm 0.3^{\mathrm{a}}$ & $70 \pm 2.1^{c}$ & $37.4 \pm 1.8^{b}$ & $\leq 0.001^{*}$ \\
\hline Dimensional changes (mm) & $0.12 \pm 0.01^{c}$ & $0.06 \pm 0.01^{\mathrm{a}}$ & $0.11 \pm 0.01^{b}$ & $\leq 0.01^{*}$ \\
\hline
\end{tabular}

Mean with different letters in the same row indicates statistically significance difference

*Significant $(p<0.05)$

The higher surface microhardness of the novel reinforced dental plaster with $10 \mathrm{wt} . \%$ aluminum oxide nanoparticle fillers may be due to the effect of incorporation of hard aluminum oxide ceramic nanoparticle fillers into gypsum products (Alhareb et al. 2017; Razak et al. 2017).

The increase in compressive strength of the reinforced dental plaster group may be due to two facts: the addition of strong aluminum oxide ceramic nanoparticle fillers into gypsum products, in addition to the reduction in calcium sulfate powder on expense of the added aluminum oxide nanoparticle filler that will lead to decrease in the formed calcium sulfate dihydrate crystals, subsequently decrease the formation of internal porosity in the set materials (Alhareb et al. 2017; Razak et al. 2017).

The little dimensional changes of the reinforced dental plaster group may be attributed to the lowest setting expansion values due to the addition of aluminum oxide nanoparticle fillers on expense of calcium sulfate dihydrate powder. Thus, reduction in the produced amount is the calcium sulfate dihydrate crystals with subsequent decrease in the resultant outward thrust action of the formed crystals, hence reduction in the linear expansion (Razak et al. 2017).

Moreover, the aluminum oxide in nanoparticle sizes has a very fine size and high surface area which may cause great interfacial interaction with matrix tha enables them to restrict the molecular motion of calcium sulfate dihydrate, thus decrease their expansion during setting (Safi 2014).

The requirement of the American Dental Association Specification No. 25 and ISO standard 6873:1998 for gypsum products that used for construction of final casts and dies included that the compressive strength values should be not less than $35 \mathrm{MPa}$. Moreover, the setting expansion should be not more than the range of 0.0-0.15\% (ADA 1985)(ISO 1998).

The null hypothesis was rejected as the innovative dental plaster reinforced by $10 \mathrm{wt} . \%$ aluminum oxide nanoparticle fillers achieved improvement in both surface microhardness and compressive strength with very little setting expansion.

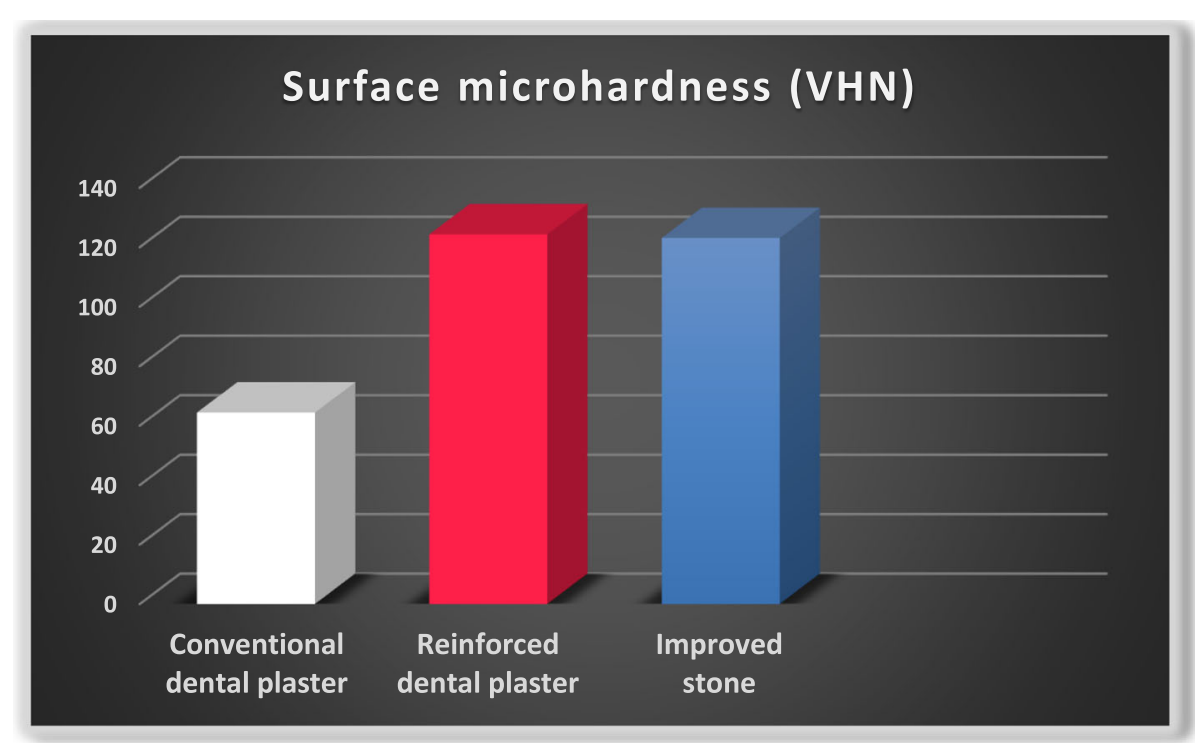

Fig. 4 Histogram demonstrating mean VHN between the three groups 


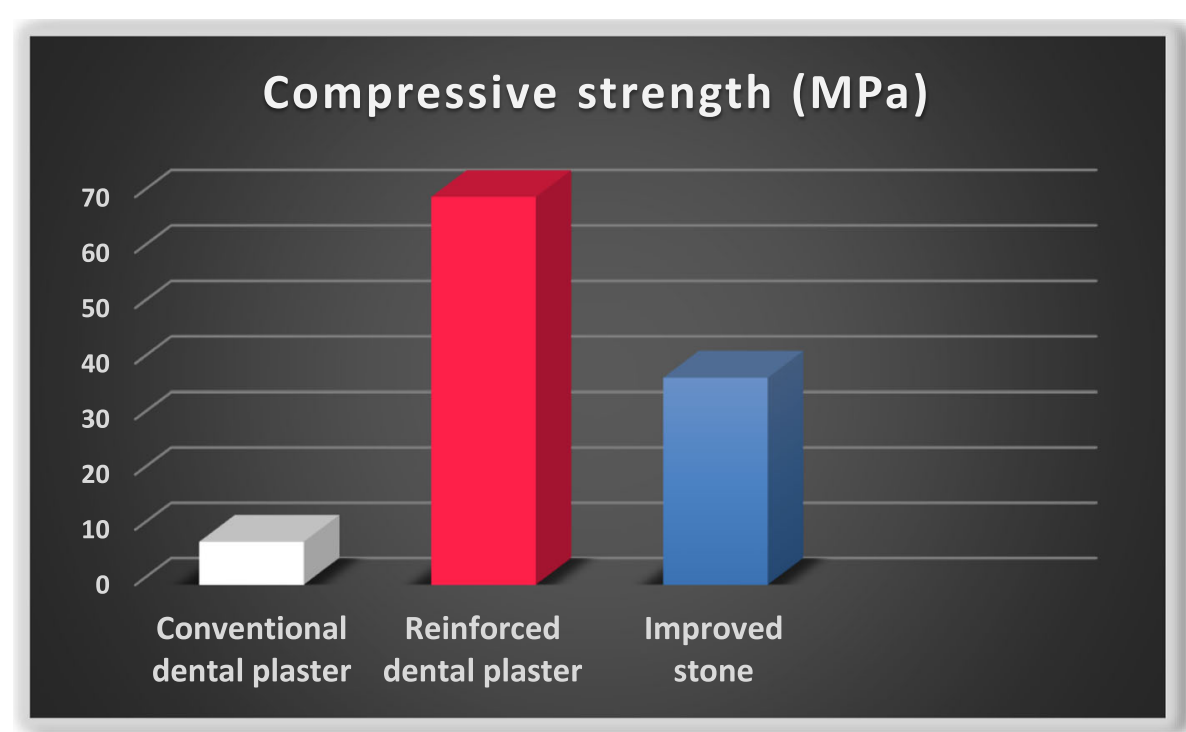

Fig. 5 Histogram illustrating mean compressive strength (MPa) values between the three groups

Our novel reinforced dental plaster gets a compressive strength values higher than those obtained from other studies that depends on the addition of glass fibers, gum Arabic, ferric oxide, and calcium oxide (Razak et al. 2017)(A Hatim et al. 2007). Furthermore, it gives a low setting expansion than study that depends on epoxy resin nanoparticle and carbone nanostructure fillers (Kreve 2018). Moreover, it gets a higher compressive strength and surface microhardness and lower setting expansion values than those of our previous investigation of microsized aluminum oxide fillers (Hamdy, 2019). Our study gives a higher compressive strength and low setting expansion than that of improved stone which not studied before.

\section{Conclusions}

Modified novel dental plaster reinforced by $10 \mathrm{wt} . \%$ aluminum oxide nanoparticle fillers could be used alternatively to the conventional improved stone (type IV) to be utilized as final cast and die materials with the highest surface microhardness and compressive strength and lowest setting expansion than that of the improved stone.

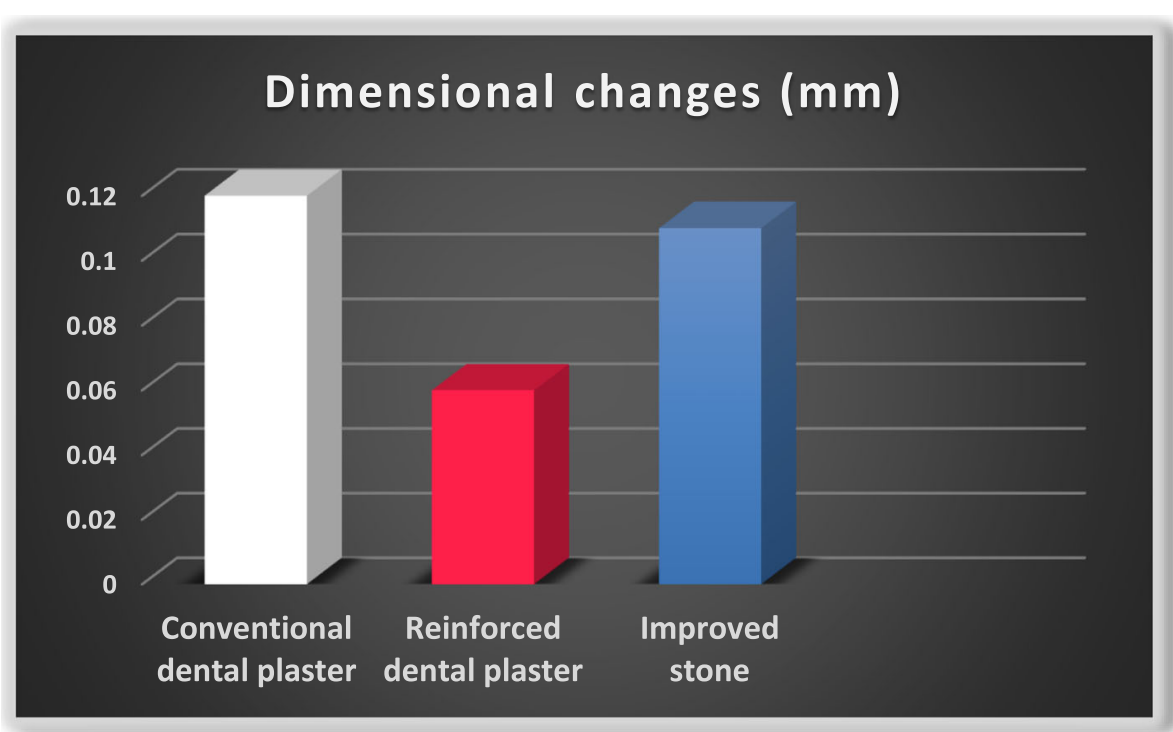

Fig. 6 Histogram showing mean dimensional changes \% between the three groups 


\section{Abbreviations}

Wt.\%: weight \%; XRF: X-ray florescence spectrometer; ADA: American Dental Association; $\mathrm{CaSO}_{4} \cdot 2 \mathrm{H}_{2} \mathrm{O}$ : Calcium sulfate hemihydrate; VHN: Vicker hardness number; ANOVA: Analysis of variance; HSD: Tukey's honestly significant difference

\section{Authors' contributions}

All authors contributed to the design and conception of the study. Tamer M. Hamdy and Rasha M. Abdelraouf performed the laboratory and experimental work. Tamer M. Hamdy investigated and interpreted the analyzed data and wrote and correspond the manuscript. Tamer M. Hamdy and Ali Abdelnabi revised and reviewed the draft manuscript. All authors check the accuracy and integrity of all part of the work and read and approved the final manuscript.

\section{Funding}

The work was self-funded by the authors.

\section{Availability of data and materials}

All data generated or analyzed during this study are included in this published article.

\section{Ethics approval and consent to participate}

Not applicable.

\section{Consent for publication}

Not applicable.

\section{Competing interests}

The authors declare that they have no competing interests.

\section{Author details}

${ }^{1}$ Restorative and Dental Materials Department, National Research Centre (NRC), El Bohouth St., Dokki, Giza 12622, Egypt. ²Biomaterials Department, Faculty of Dentistry, Cairo University, Cairo, Egypt.

Received: 28 March 2020 Accepted: 11 May 2020

Published online: 27 May 2020

\section{References}

Abdelaziz KM, Combe EC, Hodges JS (2002) The effect of disinfectants on the properties of dental gypsum, part 2: Surface properties. J Prosthodont. 11(4): 234-240

ADA (1985) Proposed addendum to ANSI/ADA specification no. 25 for dental gypsum products. J Am Dent Assoc 111(6):1003

Akkus B, Demir N, Karci M, Yazman S (2018) Compressive and diametral tensile strength of dental stones with $\mathrm{SiO} 2$ and Al2O3 nanoparticles. Int J Med Sci Innov Res

Alhareb AO, Akil HM, Ahmad ZA (2017 Jan) Impact strength, fracture toughness and hardness improvement of PMMA denture base through addition of nitrile rubber/ceramic fillers. Saudi J Dent Res. 8(1-2):26-34

AlKahtani RN (2018) The implications and applications of nanotechnology in dentistry: A review. Saudi Dental Journal 30:107-116

Darvell BW. Chapter 2 - gypsum materials. In: Materials Science for Dentistry (Tenth Edition). 2018. p. 40-69.

De Cesero L, de Oliveira EMN, Burnett Junior LH, Papaléo RM, Mota EG (2017) The addition of silica nanoparticles on the mechanical properties of dental stone. J Prosthet Dent. 118(4):535-539

dos Santos PJ, Suzuki MM, da Costa SC, Hirata BS, Lopes MB, Contreras EFR (2015) Influence of different water types on the physical and mechanical properties of gypsum. Brazilian J Oral Sci. 14(3):199-203

Hamdy TM (2019) Effect of aluminum oxide addition on compressive strength, microhardness and setting expansion of dental plaster. Int J Adv Res. 7(9): 652-657

Hatim NA, Al-Khayat I, Abdullah M (2007) Modification of gypsum products (Part I): physical and mechanical properties of adding some additives on different types of gypsum products. Al-Rafidain Dent J. 7(2):206-212

Ismail RA, Zaidan SA, Kadhim RM (2017) Preparation and characterization of aluminum oxide nanoparticles by laser ablation in liquid as passivating and anti-reflection coating for silicon photodiodes. Appl Nanosci. 7(7):477-487

ISO. Iso 6873:1998 - Dental gypsum products. International Standard. 1998.
Jayaprakash K, Upadhya P, Nandish B, Shetty A, Shetty K, Ginjupalli K et al (2014) Impact of Water Quality and Water Powder Ratio on the Properties of Type 4 - Die Stones (Gypsum Products) used in Dentistry. Int J Heal Rehabil Sci. 3(2): 75

Kenyon BJ, Hagge MS, Leknius C, Daniels WC, Weed ST (2005) Dimensional accuracy of 7 die materials. J Prosthodont. 14(1):25-31

Kreve $\mathrm{S}$. Analysis of linear dimensional change of different materials used for casting dental models: plaster type 4, nanocomposites carbon nanostructures, polyurethane resin and epoxy resin. J Dent Heal Oral Disord Ther. 2018;9(2)

Manappallil J, Manappallil J. Gypsum products. In: Basic Dental Materials. 2016. p. 310-310.

Michalakis KX, Asar NV, Kapsampeli V, Magkavali-Trikka P, Pissiotis AL, Hirayama H (2012) Delayed linear dimensional changes of five high strength gypsum products used for the fabrication of definitive casts. J Prosthet Dent. 108(3): 189-195

Products G. Learn more about gypsum replicating materials — impression and casting herbs that cool heat. 2018;(10).

Razak WA, Yassin IN, Kati FA (2017) Effect of adding some additives and drying method on compressive strength of gypsum products. Tikrit J Dent Sci. 5(2073-1213):25-32

Safi IN (2014) Evaluation the Effect of Nano - Fillers ( TiO2, AL2O3, SiO2 ) Addition on glass transition temperature , E - moudulus and coefficient of thermal expansion of acrylic denture base material. J Baghdad Coll Dent. 26(1):37-41

Subhan R, Pervaiz K, Malik S, Choudhry Z (2016) the Effect of Diverse Water Type on the Water Powder Ratio of Various Dental. Pakistan Oral Dent J 36(October):331-335

\section{Publisher's Note}

Springer Nature remains neutral with regard to jurisdictional claims in published maps and institutional affiliations.

\section{Submit your manuscript to a SpringerOpen ${ }^{\circ}$ journal and benefit from:}

- Convenient online submission

- Rigorous peer review

- Open access: articles freely available online

- High visibility within the field

- Retaining the copyright to your article

Submit your next manuscript at $>$ springeropen.com 